among boys (95\% CI 1994.9 to 2157.8 ) than girls (95\% CI 968.7 to 1085.8 ) while rural children were the most vulnerable group. Home and its premises was the most common place for the injury incidence.

Conclusion The result of the study could be an insight to the policy makers and public health planners for developing realistic and effective strategies to address the issue.

\section{UNINTENTIONAL INJURIES AMONG CHILDREN IN A LOW-INCOME COUNTRY: RESULT FORM THE LARGEST POPULATION-BASED SURVEY IN BANGLADESH}

S M Chowdhury, A Rahman, S R Mashreky, S Giasuddin, L Svanström, L G Horte, F Rahman Correspondence: Regional Office for South-East Asia, WHO, World Health House, Indraprastha Estate, Mahatma Gandhi Marg, New Delhi 110002, India

10.1136/ip.2010.029215.681

Introduction Unintentional childhood injuries are recognised as a major public health problem globally, but little is known about their patterns in most low-income countries including Bangladesh. However, no specific intervention has yet been developed to address the issue in Bangladesh.

Objectives Objectives of the paper are to explore the magnitude and distribution of unintentional injuries among Bangladeshi children ( $<18$ years). Methodology: A cross sectional survey was conducted during 2003 (January - December) in 12 randomly selected districts and Dhaka Metropolitan City of Bangladesh. Nationally representative data were collected from 171366 households comprising of 351651 children of under 18 years. Information includes the number of deaths and illness at the household in the preceding year. Verbal autopsy and verbal diagnosis form was used to determine the cause of mortality and morbidity respectively.

Results There were 351651 children in the study, of which 5577 had one or more injuries in the past 1 year. Drowning was the leading cause of injury mortality in children over 1 year of age and falls was the leading cause of injury morbidity. Incidence of unintentional injuries was significantly higher 